\title{
O MUNICÍPIO DE TUPANCIRETÃ E A RETOMADA CULTURAL POR MEIO DA PRESERVAÇÃO DA IDENTIDADE LOCAL ${ }^{1}$
}

\author{
THE MUNICIPALITY OF TUPANCIRETÃ AND THE CULTURAL RETURN \\ THROUGH THE PRESERVATION OF LOCAL IDENTITY
}

\author{
Marilia Gomes Ceolin² e Adriano da Silva Falcão ${ }^{3}$
}

\begin{abstract}
RESUMO
Este artigo é resultado da pesquisa desenvolvida para a disciplina de Trabalho Final de Graduação I, do curso de Arquitetura e Urbanismo do Centro Universitário Franciscano, o qual apresenta a proposta de implantação de um espaço de atividades múltiplas, o Largo Cultural Cine Rei, para o desenvolvimento de arte, cultura e lazer no município de Tupanciretã, região central do Estado do Rio Grande do Sul. O trabalho tem como objetivo coletar informações que darão embasamento teórico ao tema. O método de desenvolvimento compreendeu uma pesquisa qualitativa de caráter exploratório; para isso, foram realizadas coletas de dados, estudos bibliográficos e entrevistas com profissionais da área de cultura do município, que foram analisados e interpretados, para, por fim, serem feitas as considerações finais do estudo. Diante disso, constatou-se que esse resgate cultural para a sociedade tupanciretanense faz-se necessário e de extrema importância para ajudar no desenvolvimento municipal, como forma de estimular o interesse da comunidade em diferentes tipos de arte e proporcionar espaços para que as classes sociais mais baixas da população possam usufruir.
\end{abstract}

Palavras-chave: anteprojeto arquitetônico, cultura, memória local, patrimônio.

\section{ABSTRACT}

This article is the result of research developed for the discipline of Graduation Final Work I, of the course of Architecture and Urbanism of the Centro Universitário Franciscano, which presents a proposed of implantation of a space of multiple activities, the Largo Cultural Cine Rei, for the development of art, culture and leisure in the municipality of Tupanciretã, central region of the State of Rio Grande do Sul. The objective of this work is to collect information that will provide a theoretical basis to the theme. The development method comprised a qualitative research of an exploratory nature, for that were carried out data collections, bibliographic studies and interviews with professionals from the area of culture of the municipality, which were analyzed and interpreted, to finally, make the final considerations of the study. In view of this, it was found that this cultural rescue for society of Tupanciretã is necessary and extremely important to help municipal development, as way of stimulate the interest of the community in different types of art and to provide spaces for the lower layers of the population to enjoy.

Keywords: architectural draft, culture, local memory, patrimony.

\footnotetext{
${ }^{1}$ Trabalho de Iniciação Científica.

${ }^{2}$ Acadêmica do Curso Arquitetura e Urbanismo - Universidade Franciscana - UFN. E-mail: mariliaceolin.arq@gmail.com

${ }^{3}$ Orientador - Universidade Franciscana - UFN. E-mail: adriarq@ufn.edu.br
} 


\section{INTRODUÇÃO}

Este artigo foi elaborado com a finalidade de abordar o desenvolvimento histórico e a urbanização do município de Tupanciretã e suas práticas culturais e de lazer. Além disso, busca a retomada cultural da comunidade tupanciretanense por meio da preservação das edificações significativas. Mediante uma pesquisa teórica e prática, foi possível o embasamento para justificar a importância do tema proposto para a realização deste artigo.

Os objetivos deste trabalho são: buscar informações sobre o histórico da evolução urbana do município de Tupanciretã; levantar dados sobre a cultura e o lazer no município, a fim de conhecer e expor os eventos culturais que ocorrem atualmente na cidade, bem como os locais em que são realizados; difundir a ideia de resguardar a identidade local por meio da preservação de edificações, a fim de recuperar a cultura; e também, evidenciar a proposição de novos espaços, com a finalidade de valorizar e reestabelecer a cultura que está, nos dias de hoje, esquecida e insuficiente.

Por meio das análises das pesquisas bibliográficas, da coleta de dados sobre o tema abordado e de todo o estudo sobre o referencial teórico, buscou-se demonstrar a importância de novos espaços que proporcionem a recuperação cultural para a população da região de Tupanciretã.

\section{O MUNICÍPIO DE TUPANCIRETÃ}

A zona onde se encontra o município de Tupanciretã foi povoada, inicialmente, pelos índios charruas e minuanos. Com a fundação das Missões, foi estabelecida uma de suas fazendas, que ficou pertencendo aos jesuítas da Redução de São João Batista. Em 1894, após a Inauguração da ferrovia que liga Santa Maria a Cruz Alta, os revolucionários localizaram o lugar onde está situada Tupanciretã. Essa iniciativa despertou o interesse de muitos, que apostaram na nova terra a possibilidade de um futuro promissor na lavoura e na pecuária. Começaram, então, a chegar os primeiros habitantes, que criaram os ranchos e as casas. Em 21 de dezembro de 1928, foi assinado pelo Presidente do país, Getúlio Vargas, o decreto de emancipação do município de Tupanciretã (GOMES, 1994).

Após a emancipação, o município passou a ter perfil econômico muito satisfatório com grandes estâncias. Com o passar do tempo, a atividade da pecuária sofreu problemas devido a fatores econômicos, como a baixa do preço dos bovinos. Em consequência disso, as estâncias foram vendidas para agricultores que impuseram ao município grandes áreas de terra com plantações de soja, e as demais fazendas, para agricultores sem-terra que cobiçavam terras improdutivas (PREFEITURA MUNICIPAL DE TUPANCIRETÃ, s.d.).

Hoje, o município é considerado, economicamente, a capital da soja, devido à sua produção, que é a maior do Estado do Rio Grande do Sul, e à grande participação em movimentos a favor da liberação da soja transgênica (PREFEITURA MUNICIPAL DE TUPANCIRETÃ, s.d.). 
A evolução e o crescimento físico do município, resultantes do seu crescimento econômico e demográfico, traduzem-se na expansão da área urbana por meio de loteamentos, conjuntos habitacionais e/ou adensamentos que se processam nas áreas já urbanizadas e construídas (OLIVEIRA, 2011).

\section{AS EDIFICAÇÕES COM FORTE IDENTIDADE LOCAL}

Algumas edificações tiveram grande marco na história do município de Tupanciretã, entre elas, ressaltam-se duas, visando os usos para os quais foram construídas, sua localização central e seu entorno. Este se destaca, principalmente, pela proximidade com a Praça Coronel Lima e pela linha férrea que liga Santa Maria a Cruz Alta, o que as faz possuir um valor significativo para o município - não por suas características construtivas e estilísticas, mas por sua identidade local e histórica.

O primeiro edifício foi construído para ser a sede da empresa Herter \& Cia Ltda. (Figura 1), companhia privada que atua na área de automóveis e veículos automotores (revendedores da Ford), fundada em 1977. Segundo Luis Afonso Costa (2010), a empresa Herter \& Cia fazia parte da sociedade dos irmãos Luiz e Armando Herter e Sr. Adão Nonnemmacher e começou suas atividades na Rua do Comércio, hoje Avenida Vaz Ferreira. Mais tarde, com a necessidade de mais espaço, transferiu-se para a Avenida Bôrtolo Fogliatto, esquina com a Rua Coronel Luís Azevedo, próximo à linha férrea. A construção data do início dos anos 50, com assinatura do engenheiro civil Antônio dos Santos, e sua inauguração dá-se no dia 5 de maio de 1962.

Figura 1 - Vista da antiga empresa Herter \& Cia.

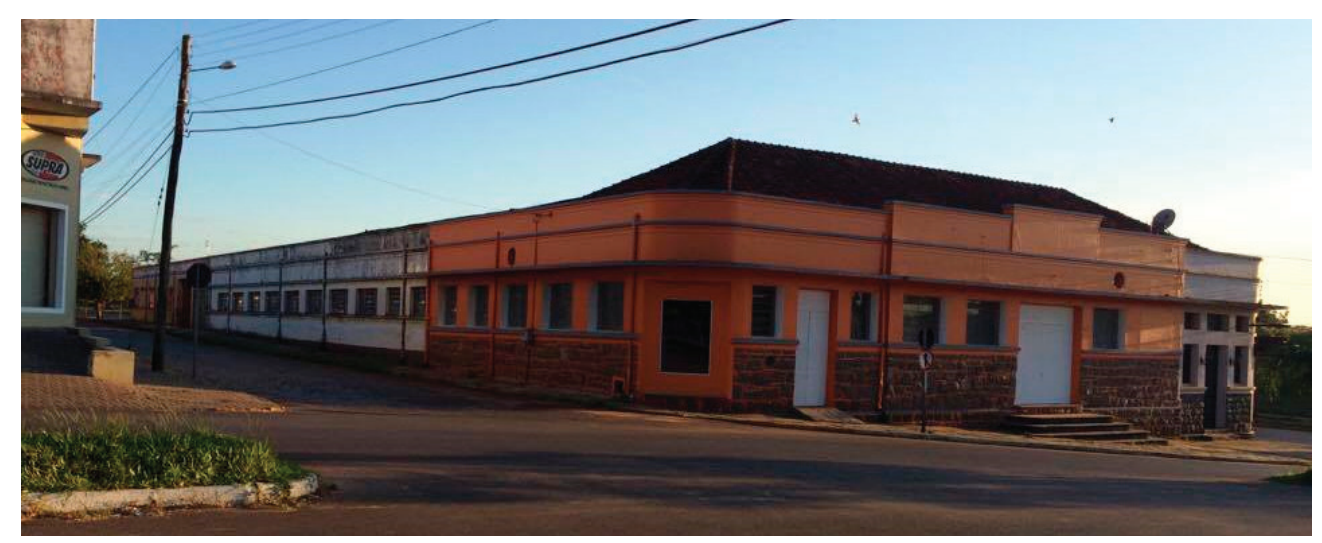

Fonte: Acervo da autora. Mar. 2017.

A segunda edificação, o antigo cinema do município de Tupanciretã, chamado Cine Rei (Figura 2), começou a ser construído em 1957. O edifício é considerado protomoderno ${ }^{4}$ e contava com uma lancheria e um salão de espetáculos que tinha capacidade para 780 espectadores. A programação

\footnotetext{
${ }^{4}$ Segundo Paulo Raposo Andrade, no texto Uma outra cultura da modernidade, entende-se "o protomodernismo como uma manifestação arquitetônica que ocorreu em diversas cidades brasileiras, entre 1930 e 1955, com características mais ou menos homogêneas, distintas, no entanto, do ecletismo historicista do início do século, como também, das experiências dos pioneiros do modernismo no Brasil".
} 
do Cine Rei era lançada pela Empresa Espelet e era considerada excelente na época, sendo rodado um filme por dia, em que somente fitas nacionais tinham prioridade de reprise (GOMES, 1994).

Figura 2 - Vista do antigo Cine Rei.

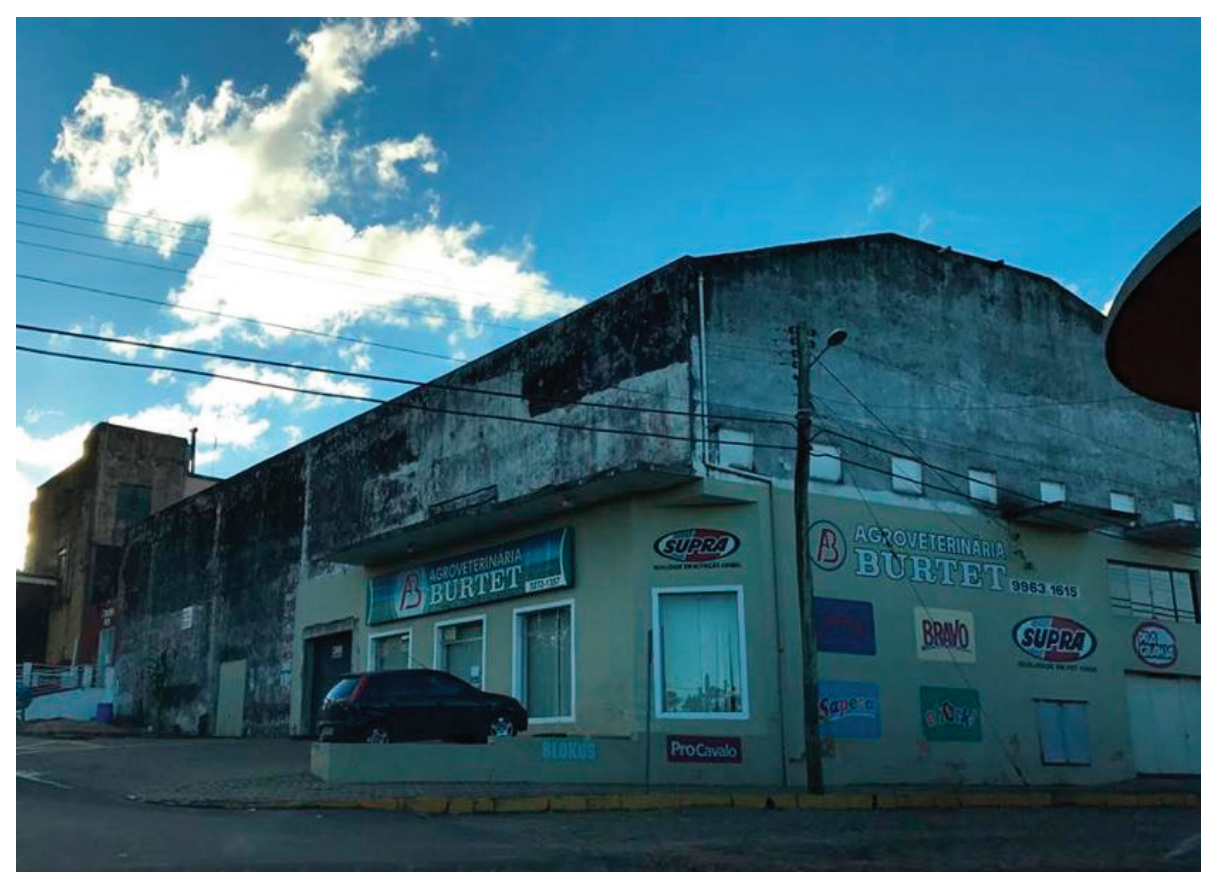

Fonte: Acervo da autora. Mar. 2017.

As duas edificações tiveram funções iniciais importantes para o município de Tupanciretã: cultural, no caso do antigo Cine Rei, e econômica, no caso da antiga sede da empresa Herter \& Cia. Isso porque o antigo cinema municipal reunia a comunidade para a participação em diversos eventos, como mostra a Figura 3.

Figura 3 - Participação da comunidade em um evento no antigo Cine Rei, em 1978.

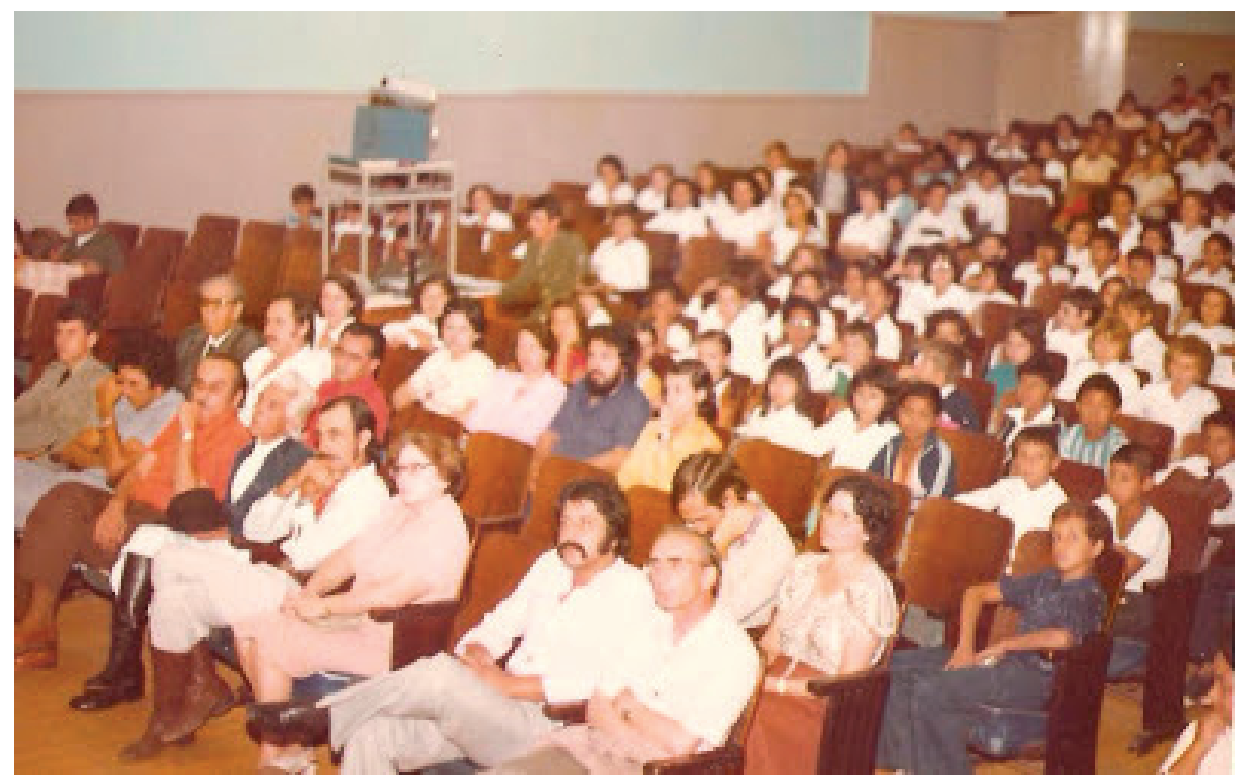

Fonte: Luis Afonso Costa - blogger. Set. 2010. 
Já a antiga Herter \& Cia movimentava o comércio do município com sua atuação na área automotiva e, desde a sua inauguração, contava com a presença e o benefício da comunidade, como ilustra a Figura 4.

Figura 4 - Inauguração da sede da empresa Herter \& Cia, em 1962.

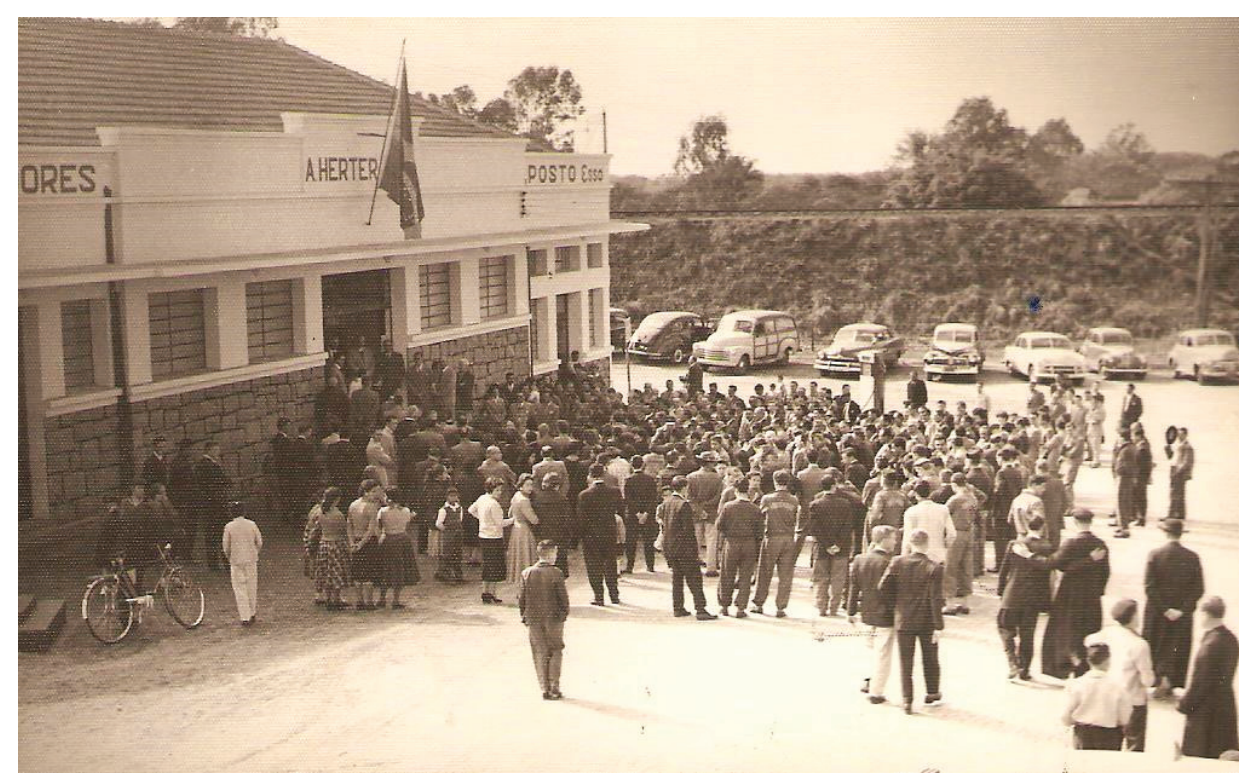

Fonte: Luis Afonso Costa - blogger. Jun. 2010.

Em vista disso, as edificações tiveram grande valor histórico, econômico e cultural para o desenvolvimento municipal. Porém, atualmente, encontram-se em estado precário e com usos diferenciados e variados: a antiga revendedora passou a abrigar um restaurante, uma sala de danças, oficinas e posto de lavagem de automóveis; e o antigo cinema deu lugar a setores de comércio e a um bar, porém grande parte de sua área encontra-se sem uso.

\section{A CULTURA E O LAZER EM TUPANCIRETÃ}

A Administração Municipal de Tupanciretã, por meio da Secretaria Municipal de Esporte, Cultura e Lazer, oferta à população tupanciretanense alguns eventos que promovem a integração de diferentes classes e faixas etárias, como:

- a Abertura Oficial da Colheita da Soja do Estado do Rio Grande do Sul, evento oficial do Governo do Estado, onde é promovida oficialmente a abertura da colheita da soja;

- o Baile da Escolha da Corte Municipal de Carnaval, que promove a integração da Comunidade Carnavalesca; 
- as Competições Escolares, que incentivam a prática de exercícios no ambiente escolar;

- a Feira do Livro (Figura 5), que tem como objetivo oportunizar à comunidade escolar e à comunidade em geral o acesso à leitura;

- teatros e palestras, para proporcionar e estimular o desenvolvimento intelectual e social da sociedade;

- e projetos sociais que visam à descoberta de talentos locais e ao incentivo à prática de esporte na comunidade.

Figura 5 - Feira do Livro em Tupanciretã.

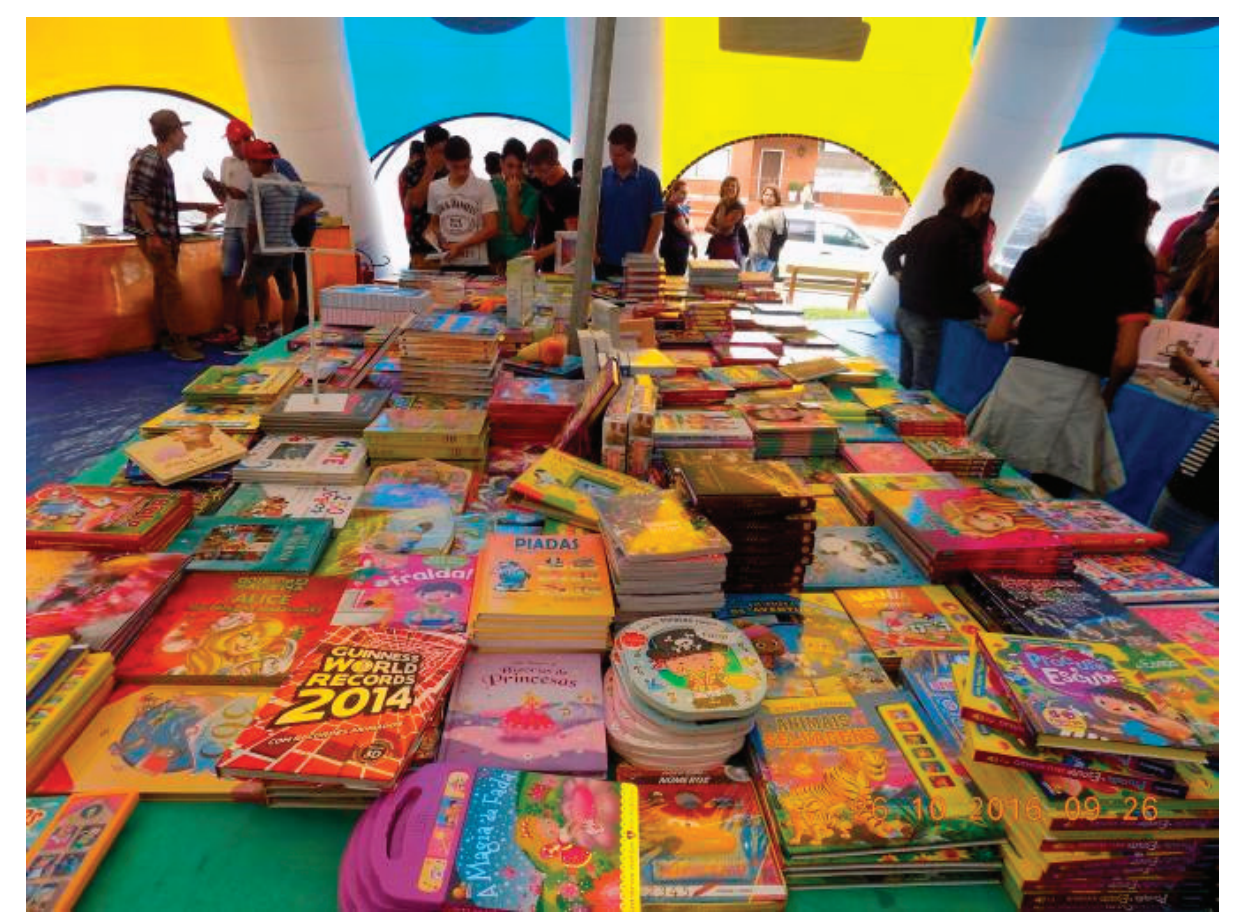

Fonte: Prefeitura Municipal de Tupanciretã. Out. 2016.

Em entrevista informal com a Secretária Municipal de Esporte, Cultura e Lazer, Janete Lucia Secchi, foi relatada a dificuldade em oferecer diferentes eventos culturais e de lazer na cidade, levando em consideração espaços insuficientes ou inadequados para tais atividades.

Os espaços para esses eventos, em sua maioria, são em frente à Praça Coronel Lima, na Avenida Vaz Ferreia, sendo esta interrompida para o trânsito de veículos, como mostra a Figura 6 (um teatro infantil, em que as crianças estão sentadas no calçamento da via); em ginásios poliesportivos; ou na Casa de Cultura Municipal, onde as condições de conforto e segurança dos ocupantes não satisfazem às necessidades. 
Figura 6 - Teatro infantil na Avenida Vaz Ferreira.

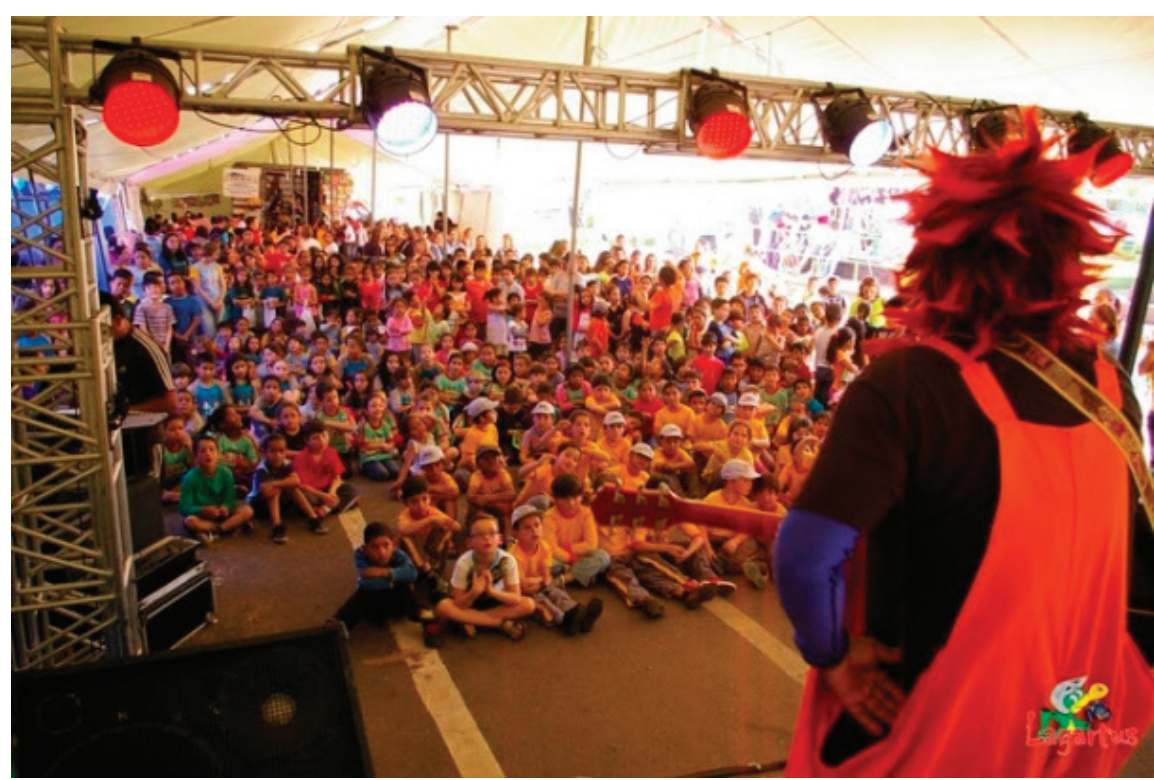

Fonte: Luis Afonso Costa - blogger. Out. 2011.

O município possui uma elevada quantidade de eventos, contudo faltam espaços adequados para tais atividades, tendo-se, assim, a necessidade de se incentivarem essas iniciativas municipais com a implantação de espaços mais apropriados e reservados exclusivamente para a prática cultural e de lazer. Isso teria a finalidade de estimular o interesse da comunidade tupanciretanense em diferentes tipos de arte e, principalmente, oferecer espaços adequados e seguros para a população.

\section{A IMPORTÂNCIA DA PRESERVAÇÃO DA IDENTIDADE LOCAL COMO INCENTIVADOR CULTURAL}

A cultura é definida por Canclini (2008 apud PICHLER; MELLO, 2012) como um fenômeno que, mediante símbolos e representações, auxiliam na reprodução ou transformação do sistema social, ou seja, ela é um processo de produção de significados que são capazes de manter ou modificar maneiras de viver, ideias e valores.

Já a identidade local é definida por um grupo de pessoas que vivem em um mesmo lugar e dividem experiências e conhecimentos.

Lugar, entretanto, não deve ser compreendido apenas como o espaço onde se realizam as práticas diárias; mas também como aquele no qual se situam as transformações e a reprodução das relações sociais de longo prazo, bem como a construção física e material da vida em sociedade. Nele, realiza-se o cotidiano, o momento, o fugidio; mas também a história, o permanente, o fixo, correspondendo ao identitário, ao relacional e ao histórico, no âmbito da tríade habitante-identidade-lugar (ALBAGLI, 1999 apud ALMEIDA; DANTAS; GUIMARÃES, 2008). 
Conforme Fernandes e Canatá (2010), os projetos de reabilitação não se limitam às áreas dos centros históricos ou ao patrimônio classificado, mas, sim, a todos os lugares privados por diferentes motivos.

Reabilitar, hoje mais do que nunca, significa fundamentalmente recuperar as qualidades perdidas e integrar ao mesmo tempo aquelas características necessárias para que o território em causa continue a viver com as condições de conforto e beleza (FERNANDES; CANNATÁ, 2010, p. 9).

Nesse contexto, segundo as teorias de Brandi (1963), a preservação do patrimônio cultural, em suas diversas formas e aspectos, consolidou seu espaço na sociedade contemporânea, contribuindo para a democratização do acesso e da fruição da cultura. A partir disso, o autor ensina que "a restauração constitui o momento metodológico do reconhecimento da obra de arte, na sua consistência física e na sua dúplice polaridade estética e histórica, com vistas à sua transmissão para o futuro" (BRANDI, 2016, p. 30).

Para Milanesi (1997), é necessário manter, na medida do possível, o equilíbrio entre a preservação e a funcionalidade. Segundo ele, os antigos cinemas são opções frequentes para essa metamorfose, pois prende-se à memória: “afinal, o velho cine é uma das referências da cidade, local de tantos acontecimentos e de valor sentimental" (MILANESI, 1997, p. 68).

De acordo Oliveira (2011), a arquitetura e os espaços constituem o cenário onde as lembranças situam-se e consolidam relações de identidade importantes para a comunidade em geral, pois estabelecem importantes vínculos entre espaço e cidadania.

Nesse sentido, o resgate da memória é de suma importância devido à construção de uma identidade consistente de um determinado povo. Para isso, é necessário que não se deixe de rememorar, ir à busca das raízes, das origens, do âmago da sua história (BATISTA, 2005 apud PINTO; PAULO; SILVA, 2012).

Dessa maneira, preservar uma edificação, além de restabelecer a funcionalidade ou trazer novos usos a um edifício que, muitas vezes, está desabilitado e descuidado, resgata a história e a cultura desse local, que, de certa forma, teve uma importância para a comunidade, seja social, cultural ou histórica.

\section{A PROPOSIÇÃO DE NOVOS ESPAÇOS COMO FORMA DE VALORIZAÇÃO CULTURAL}

A demanda por um local de alternativas socioculturais e recreativas para a sociedade tupanciretanense, bem como o estado de precariedade em que se encontram as edificações existentes na área de intervenção, tendo em vista a perda de seus fins construtivos, requerem um restabelecimento de ocupações dos edifícios como uma maneira de recuperar e valorizar a cultura local. Além disso, essa intervenção é uma forma de resgatar a memória e reintegrar antigos costumes da comunidade - como a frequência em eventos no antigo cinema municipal, o Cine Rei - e ressaltar elementos identitários para a 
população em geral, com espaços que estimulem o desenvolvimento intelectual e social - unindo, assim, diversos grupos e faixas etárias - e que permitam uma interação de ideias, crenças e costumes.

Ademais, como elucidado anteriormente, preservar a identidade local e estabelecer novos usos para as edificações será uma forma de incentivar a cultura no município, desenvolver novas ideias e recuperar a arquitetura da cidade.

Para Milanesi (1997), um espaço cultural deve estabelecer quais os objetivos e as funções a serem ofertados pelo equipamento. $\mathrm{O}$ arquiteto, ao planejar um centro cultural, deve considerar a necessidade de espaços para o acesso ao conhecimento, para a convivência e para a criação.

\begin{abstract}
O centro de cultura é um espaço que deve construir laços com a comunidade e os acontecimentos locais, funcionando como um equipamento informacional, no qual proporciona cultura para os diferentes grupos sociais, buscando promover a sua integração. Um espaço cultural, além de exercer atividades culturais diversificadas, deve possuir no programa de necessidades atributos ambientais essenciais para o seu bom funcionamento e qualidade de bem-estar do usuário (NEVES, 2013, p. 1).
\end{abstract}

Diante desse contexto, os centros culturais são espaços que conservam, difundem as artes e expõem testemunhos materiais produzidos pelo homem. No Brasil, há 2.500 centros culturais, entre museus, teatros e bibliotecas, que mantêm acervos e exposições. Com eles, o cidadão entra em contato com diversas manifestações artísticas e pode desenvolver um olhar mais crítico sobre a cultura e outros aspectos de seu cotidiano (PORTAL BRASIL, 2009).

Desse modo, criar novos espaços culturais é de suma importância para o desenvolvimento de uma comunidade, pois inclui diferentes classes sociais no âmbito cultural, oferecendo condições para que todos tenham acesso às atividades de arte, cultura e lazer, como um estimulador intelectual de modo a valorizar a cultura local.

\title{
LARGO CULTURAL CINE REI - UMA PROPOSTA DE INCENTIVO CULTURAL E SOCIAL
}

O anteprojeto arquitetônico e urbanístico do Largo Cultural Cine Rei consiste na elaboração de um espaço de atividades múltiplas, o qual tem por intuito o desenvolvimento cultural, por meio de espaços interativos vinculados ao lazer e ao entretenimento para o município de Tupanciretã, Rio Grande do Sul.

O objetivo geral do projeto é desenvolver um espaço que possa abrigar diferentes equipamentos culturais e de lazer para o desenvolvimento de projetos municipais que também proporcionem ocupações de contraturno escolar para crianças e adolescentes, com uma utilização permanente durante o período anual. É imprescindível que o projeto disponha de atrativos para todas as faixas etárias, de forma que contemplem um amplo público-alvo. Para isso, foi pensado um espaço único 
para cinema e teatro; oficinas de música, dança e arte; espaço aberto para eventos e alimentação; e um “espaço memória”, para reunir expressões artísticas que relembrem a história do município.

O projeto também busca desenvolver novas ideias e recuperar a arquitetura da cidade, trabalhando com as duas edificações existentes - a antiga sede da empresa Herter \& Cia e o antigo Cine Rei -, citadas anteriormente, e progredindo também no urbanismo, pois visa à criação de um espaço público e de lazer, almejando a reorganização do espaço urbano a conexão entre as duas edificações.

A visão de um novo espaço cultural em Tupanciretã surge como um incentivador social para o município, tendo em vista a carência da região em alternativas socioculturais e recreativas. Considera-se que a criação desse local possa suprir as necessidades da cidade e atender à sua demanda, com espaços que estimulem o desenvolvimento intelectual e social de diversos grupos e faixas etárias.

\section{CONSIDERAÇÕES FINAIS}

A partir das análises desenvolvidas nesta pesquisa, confirma-se a importância de espaços culturais para a comunidade tupanciretanense, para que estimulem o desenvolvimento intelectual e social de diversas faixas etárias e permitam uma interação de ideias, crenças e costumes, tendo em vista a carência da região em espaços socioculturais.

Também se percebe a importância de preservar as edificações, como uma forma de ressaltar elementos identitários para a população, e restabelecer novos usos para reavivar os antigos costumes da comunidade.

Essa pesquisa também proporcionou a criação de um embasamento teórico que irá auxiliar no desenvolvimento do anteprojeto arquitetônico e urbanístico do Largo Cultural Cine Rei, que será situado no município de Tupanciretã. Após a organização e análise dos dados obtidos, chegou-se à conclusão de que a proposição desse novo equipamento no município será de grande valor e relevância para o desenvolvimento cultural de toda a comunidade.

\section{REFERÊNCIAS}

ALMEIDA, J. D.; DANTAS, L. C.; GUIMARÃES, L. E. C. A intervenção do design e a valorização de produtos artesanais em base territorial: estudos de caso do Rio Grande do Norte. In: XXVIII ENCONTRO NACIONAL DE ENGENHARIA DE PRODUÇÃO - ENEGEP: Rio de Janeiro, 2008. Disponível em: https://bit.ly/2XH7mOi. Acesso em: 20 jun. 2017.

ANDRADE, P. R. Uma outra cultura da modernidade. São Paulo: AU (Arquitetura e Urbanismo), 1994. 
BRANDI, C. Teoria da restauração. 4. ed., v. 2. (Beatriz Mugayar Kühl Trad.) Cotia: Ateliê Editorial, 2016.

COSTA, L. A. Tupanciretã, Herter \& Cia, parte I: obra na Bortolo Fogliatto x Cel. Luiz Azevedo, 2010. Disponível em: https://bit.ly/2XFrwZf. Acesso em: 23 mar. 2017.

COSTA, L. A. Feira do livro 2011 em Tupanciretã, 2011. Disponível em: https://bit.ly/3akXAUO. Acesso em 24 mar. 2017.

FERNANDES, F.; CANNATÁ, M. Territórios reabilitados. Portugal: Editora Caleidoscópio, 2010.

GOMES, M. A. Tupanciretã: alvorada de sonhos. Porto Alegre: Editora Alcance, 1994.

MILANESI, L. A casa da invenção: Biblioteca Centro de Cultura. 3. ed. São Caetano do Sul: Ateliê Editorial, 1997.

NEVES, R. R. Centro cultural: a cultura à promoção da arquitetura. Revista Especialize On-line IPOG. 5. ed., v. 1, n. 005. Goiânia, jul. 2013. Disponível em: https://bit.ly/3csbsOI. Acesso em: 24 jun. 2017.

OLIVEIRA, T. D. Patrimônio edificado de Tupanciretã/RS: um olhar sobre o patrimônio arquitetônico e cultural da Terra da mãe de Deus. Santa Maria: UFSM, 2011. Disponível em: https://bit.ly/ 2XH7wVU. Acesso em: 22 jun. 2017.

OLIVEIRA, T. D. Reflexões sobre a infraestrutura e a influência destas na qualidade de vida da população urbana de Tupanciretã/RS. In. XVI SEMINÁRIO INTERINSTITUCIONAL DE ENSINO, PESQUISA E EXTENÇÃO. Cruz Alta: UNICRUZ, 2011. Disponível em: https://bit.ly/ 34HZKgd. Acesso em: 22 jun. 2017.

PICHLER, R. F.; MELLO, C. I. O design e a valorização da identidade local. Design E Tecnologia, 2(04), 1-9. UFRGS, 2012.

PINTO, G. B.; PAULO, E.; SILVA, T. C. Os centros culturais como espaço de lazer comunitário: o caso de Belo Horizonte. Cultur Revista de Cultura e Turismo. Ano 6. n. 02 jun. 2012. Disponível em: https://bit.ly/2Vf00A8. Acesso em: 24 jun. 2017. 
PORTAL BRASIL. Centros Culturais, 2009. Disponível em: https://bit.ly/2VkqqRb. Acesso em: 23 mar. 2017.

PREFEITURA MUNICIPAL DE TUPANCIRETÃ. História do Município, (s.d.). Disponível em: https://bit.ly/2VPN2rN. Acesso em: 23 mar. 2017. 